\title{
Taming Phosphorus Mononitride (PN)
}

André K. Eckhardt, ${ }^{a}$ Martin-Louis Y. Riu, ${ }^{a}$ Mengshan Ye, ${ }^{a}$ Peter Müller, ${ }^{a}$ Giovanni Bistoni, ${ }^{b}$ and Christopher C. Cummins ${ }^{\mathrm{a}, *}$

${ }^{a}$ Department of Chemistry, Massachusetts Institute of Technology, Cambridge MA, USA;

*ccummins@mit.edu

${ }^{\mathrm{b}}$ Max-Planck-Institut für Kohlenforschung, Kaiser-Wilhelm-Platz 1, 45470 Mülheim an der Ruhr, Germany

Keywords: Azide - Phosphorus - Small Molecule Activation - Thermolysis - Transition Metal Chemistry

\begin{abstract}
Phosphorus mononitride (PN) only has a fleeting existence on Earth and molecular precursors for a mild release of the molecule to enable chemical synthesis in solution do not exist. Here we report the synthesis of an anthracene (A) based molecular precursor $\left(\mathrm{N}_{3} \mathrm{PA}\right)$ that dissociates into dinitrogen $\left(\mathrm{N}_{2}\right)$, A and PN in solution with a first order half-life of roughly $t_{1 / 2}=30 \mathrm{~min}$ at room temperature associated with an activation enthalpy of $\Delta H^{\ddagger}=19.5 \pm 1.7 \mathrm{kcal} \mathrm{mol}^{-1}$ and an activation entropy of $\Delta S^{\ddagger}=-8.8 \pm 0.8 \mathrm{cal} \mathrm{mol}^{-1} \mathrm{~K}^{-1}$. Heated under vacuum $\mathrm{N}_{3} \mathrm{PA}$ decomposes in an explosive fashion at around $42{ }^{\circ} \mathrm{C}$ as demonstrated in a molecular beam mass spectrometry (MBMS) study. $\mathrm{N}_{3}$ PA serves as a PN transfer reagent as demonstrated in the synthesis $\left[(\mathrm{dppe}) \mathrm{Fe}\left(\mathrm{Cp}^{*}\right)(\mathrm{NP})\right]\left[\mathrm{BArF}_{24}\right]$. Surprisingly, the terminal $\mathrm{N}$-bonded linkage isomer is energetically preferred due to significant covalent iron pnictogen bond character and associated less unfavorable Pauli repulsion in the metal-ligand interaction.
\end{abstract}

The dinitrogen analogue phosphorus mononitride is the first phosphorus containing compound detected in the interstellar medium in 1987.1,2 On Earth, PN was first accidentally prepared in a discharge through air in a tube, which previously had been used with phosphorus by Herzberg et al. in 1933 and spectroscopically characterized based on 24 rotational bands. ${ }^{3}$ Previously Moldenhauer already reported the formation of a remarkably stable yellow powder in a discharge through nitrogen and phosphorus with a stoichiometry of equal amounts of phosphorus and nitrogen. ${ }^{4}$ Alternatively, monomeric PN is formed in the high-vacuum flash pyrolysis of $\mathrm{P}_{3} \mathrm{~N}_{5}$ at $800-900{ }^{\circ} \mathrm{C}$, isolated in solid krypton at $10 \mathrm{~K}$, and characterized based on its single infrared fundamental at $1323 \mathrm{~cm}^{-1} .5$ In the absence of a noble gas matrix PN polymerizes to $[\mathrm{PN}]_{n}$ and aromatic cyclotriphosphazene $(\mathrm{PN})_{3}$, which also forms in electron irradiation experiments of ammonia $\left(\mathrm{NH}_{3}\right)$ and phosphine $\left(\mathrm{PH}_{3}\right)$ containing ices ${ }^{6}$ at cryogenic temperatures. ${ }^{7}$ The cyclotriphosphazene molecule undergoes a photochemically induced rearrangement to its Dewar benzene-type valence isomer. Under matrix isolation conditions $\mathrm{PN}$ was reported to interact with different metal atoms, including $\mathrm{Cu}, \mathrm{Ag}, \mathrm{Au}, \mathrm{Co}, \mathrm{Ni}$ and $\mathrm{Pd}{ }^{8}$ $A b$ initio computations indicate that $\mathrm{PN}$ is thermodynamically unstable and formation of $\mathrm{N}_{2}$ and 
diphosphorus $\left(\mathrm{P}_{2}\right)$ is exergonic. ${ }^{9}$ Klapötke et al. described with $\mathrm{P}_{3} \mathrm{~N}_{21}$ the smallest structurally characterized discrete binary $\mathrm{PN}$ molecule so far. ${ }^{10}$

The stabilization and activation of dipnictogens, e.g., $\mathrm{N}_{2},{ }^{11} \mathrm{P}_{2},{ }^{12,13}$ and just recently $\mathrm{PN}^{14}$ is still an ongoing endeavor in inorganic chemistry. Due to its high reactivity and the absence of a suitable molecular precursor for a mild release of PN, molecules containing embedded phosphorus mononitride units have been synthesized and stabilized in various fashions, e.g., N-heterocyclic carbenes, ${ }^{15}$ anthracene (APNA),${ }^{16}$ or cyclo-tetraphosphazene. ${ }^{17}$ Niecke and coworkers reported with iminophosphenium tetrachloroaluminate (1, Figure 1 top left) the first stable compound with a PN triple bond of 1.475(8) $\AA$ according to a crystallographic study. ${ }^{18}$ The Bertrand group reported the stabilization of $\mathrm{PN}$ by two N-heterocyclic carbenes (2, Figure 1 top middle). ${ }^{15}$ However, the central $\mathrm{P}-\mathrm{N}$ interatomic distance was reported in the crystal structure as 1.709(2) $\AA$, which is significantly longer than the triple bond in the gaseous PN molecule determined by microwave spectroscopy to be $1.49086(2) \AA .{ }^{19}$ Hence, a better description for the compound would be $\mathrm{R}^{\prime} \mathrm{R}{ }^{\prime}{ }^{\prime} \mathrm{C}=\mathrm{P}-\mathrm{N}=\mathrm{CR}_{2}$ instead of $\mathrm{R}$ ' $\mathrm{R}$ ' $\mathrm{C} \rightarrow \mathrm{P} \equiv \mathrm{N} \leftarrow \mathrm{CR}_{2}{ }^{20}$, 21 A similar result was observed by doubly anthracene stabilized PN in APNP (Figure 1 top right). ${ }^{16}$ However, from none of these PN-containing complexes could free molecular PN be released, yet. Even the isolation of metal complexes with a PN ligand seems to be challenging because of rapid oligomerization reactions as demonstrated by the phosphinidene reactivity of the transient $\mathrm{PNV}\left(\mathrm{N}\left[{ }^{t} \mathrm{Bu}\right] \mathrm{Ar}\right)_{3}\left(\mathrm{Ar}=3,5-\mathrm{Me}_{2} \mathrm{C}_{6} \mathrm{H}_{3}\right)$ complex. ${ }^{22}$ Only just recently, Martinez et al. reported the synthesis of the first crystallographically characterized $\mathrm{PN}$ transition metal complex, namely $\left[\left(\mathrm{N}_{3} \mathrm{~N}\right) \mathrm{Mo}-\mathrm{P} \equiv \mathrm{N}\right]^{-}\left([\mathrm{Mo}](\mathbf{P N})^{-}\right), \mathrm{N}_{3} \mathrm{~N}=\left[\left(\mathrm{Me}_{3} \mathrm{SiNCH}_{2} \mathrm{CH}_{2}\right)_{3} \mathrm{~N}\right]^{3-}$, which undergoes light-induced linkage isomerization to provide $\left[\left(\mathrm{N}_{3} \mathrm{~N}\right) \mathrm{Mo}-\mathrm{N} \equiv \mathrm{P}\right]^{-}\left([\mathrm{Mo}](\mathbf{N P})^{-}\right)$, as revealed by photocrystallography (Figure 1, bottom). ${ }^{14}$ The mononuclear PN complex was released in a reaction of ${ }^{t} \mathrm{BuNC}$ with a bridging PN heterodinuclear complex that was initially synthesized in a reductive coupling of iron(IV) nitride and molybdenum(VI) phosphide complexes. ${ }^{14}$
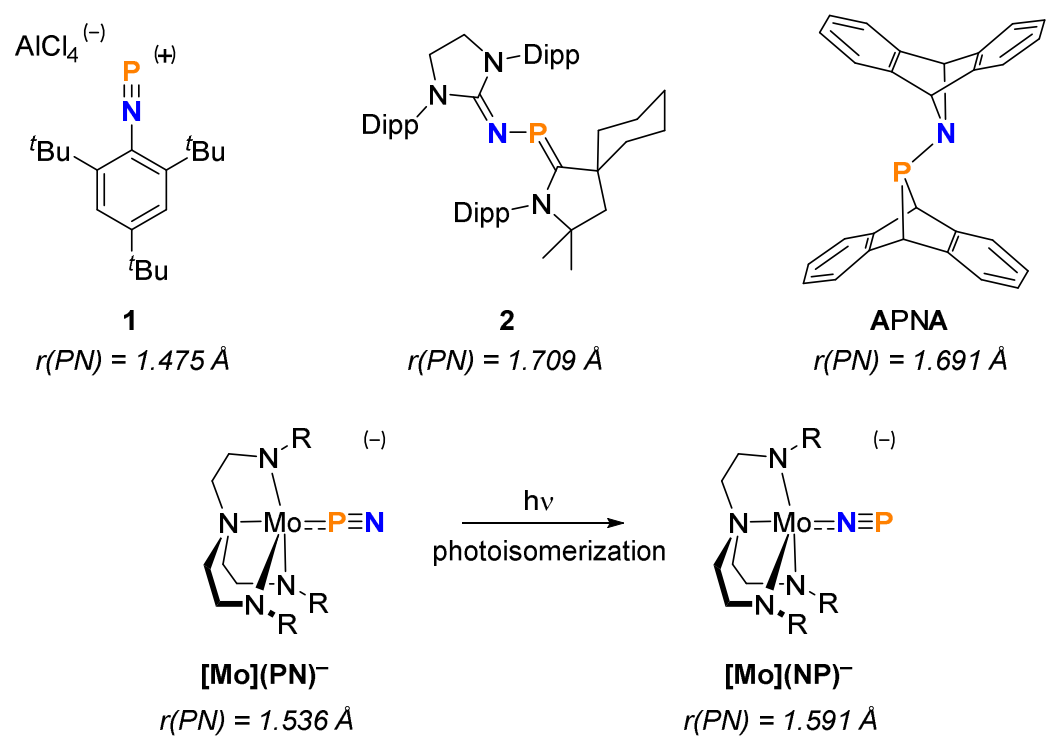

[Mo](NP)-

$r(P N)=1.591 \AA$

Figure 1 | Selected PN containing molecules and transition metal complexes with given PN bond distances. Top: Iminophosphenium tetrachloroaluminate (1, left) as the first stable compound with a PN triple bond $(1.475(8)$ $\AA$ ). Phosphorus mononitride trapped between two N-heterocyclic carbenes (2, middle) and two molecules of anthracene (APNA, right) with PN bond distances of 1.709(2) $\AA$ and 1.691(1) $\AA$, respectively. Bottom: Anionic molybdenum complex with a PN ligand that isomerizes by irradiation with white light; The PN bond lengths

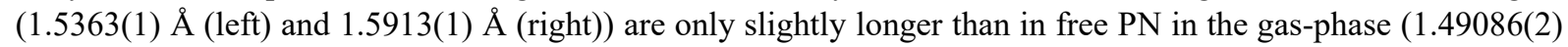
$\AA)$. 
Here we report the synthesis of an anthracene based molecular precursor for the release of molecular PN under standard laboratory conditions. In the past dibenzo$7 \lambda^{3}$-phosphanorbornadiene derivatives have already served as suitable precursors for the release of small phosphorus bearing molecules with only anthracene as a leaving group and byproduct. ${ }^{16,23-26}$ According to the literature chlorophosphine $\mathrm{ClPA}^{23}$ was synthesized and stirred with an excess of sodium azide ( $\mathrm{NaN}_{3}, 5$ equiv.) in tetrahydrofuran (THF) at $-20{ }^{\circ} \mathrm{C}$. The addition of lithium chloride ( $\mathrm{LiCl}, 2$ equiv.) as a phase-transfer catalyst $\mathrm{t}^{27}$ to solubilize azide ions through conversion of insoluble $\mathrm{NaN}_{3}$ into soluble $\mathrm{LiN}_{3}$ and $\mathrm{NaCl}$ proved to be highly efficient in reducing the reaction time to 7-10 days and a crude yield of azidophosphine $\mathrm{N}_{3} \mathrm{PA}$ as a colorless solid of up to $70 \%$ after workup (Scheme 2, Figure S1-S3). Single crystals of $\mathrm{N}_{3} \mathrm{PA}$ grown from diethyl ether at $-20{ }^{\circ} \mathrm{C}$ were characterized in a single crystal X-ray diffraction experiment and the molecular structure is depicted in Figure 2A (see also Table S3). The structure is in line with a strong infrared band for the azide functional group at $2042 \mathrm{~cm}^{-1}$ (Figure S6) and a single signal in the proton decoupled ${ }^{31} \mathrm{P}\left\{{ }^{1} \mathrm{H}\right\}$ NMR spectrum at $\delta 180.6 \mathrm{ppm}$ (Figure S2) that is split into a triplet in the proton coupled ${ }^{31} \mathrm{P}$ NMR spectrum with a coupling constant to the two bridgehead protons of anthracene of ${ }^{2} J_{\mathrm{PH}}=14.5 \mathrm{~Hz}$. Isotopically ${ }^{15} \mathrm{~N}$ labeled $\mathrm{N}_{3} \mathrm{PA}$, was synthesized from sodium azide- $1-{ }^{15} \mathrm{~N}$ following the same procedure. We obtained a statistical mixture with the ${ }^{15} \mathrm{~N}$ isotope bonded to phosphorus as well as at the terminal end of the azide unit. Due to ${ }^{31} \mathrm{P}_{-}{ }^{15} \mathrm{~N}$ coupling the signal in the ${ }^{31} \mathrm{P}\left\{{ }^{1} \mathrm{H}\right\}$ NMR is split into a doublet that overlaps with the singlet for the terminal ${ }^{15} \mathrm{~N}$ labeled $\mathrm{N}_{3} \mathrm{PA}$ (Figure S4). The singlet is not exactly in the center of the doublet because of the isotopic shift. ${ }^{28,29}$ We observed two singlet signals at $\delta 310$ and $\delta 197 \mathrm{ppm}$ in the ${ }^{15} \mathrm{~N}$ NMR for both isotopologues that, however, did not split into doublets (Figure S5).

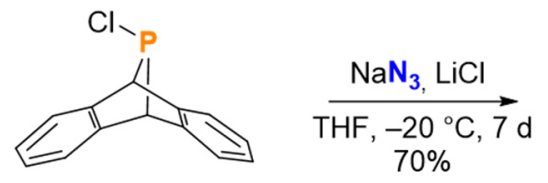

CIPA
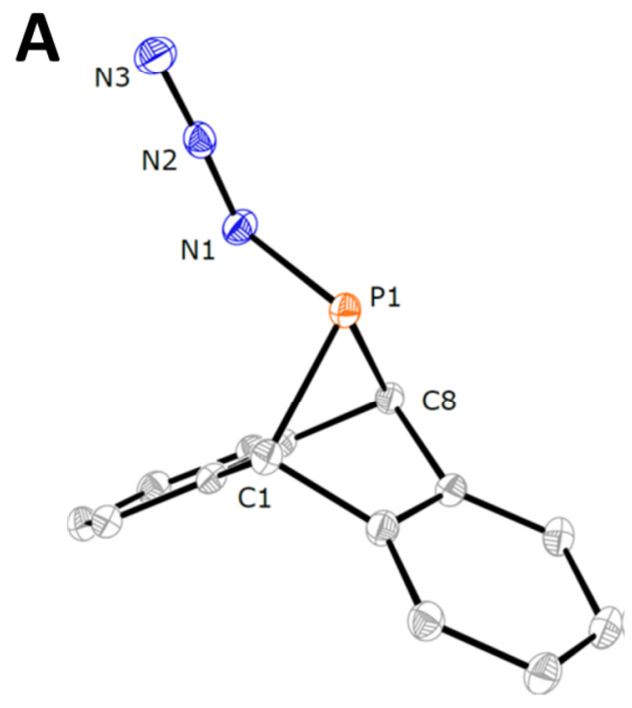

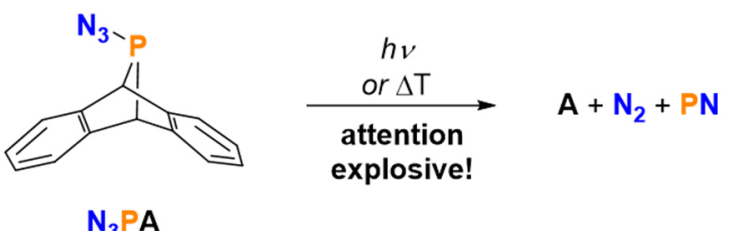

B

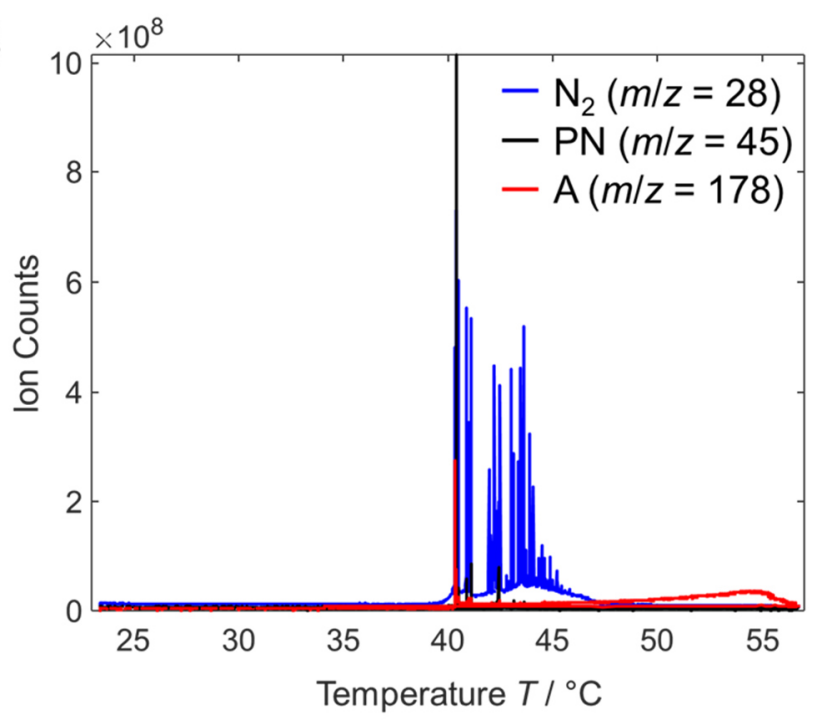

Figure 2 Synthesis, structure and decomposition of $\mathbf{N}_{3} \mathbf{P A}$. Top: Synthesis of $\mathrm{N}_{3}$ PA by nucleophilic substitution of CIPA with $\mathrm{NaN}_{3}$, catalysed by $\mathrm{LiCl}$ in THF at $-20{ }^{\circ} \mathrm{C}$. A: Molecular structure of $\mathrm{N}_{3} \mathrm{PA}$ with thermal ellipsoids shown at the $50 \%$ probability level. Hydrogen atoms are omitted for the sake of clarity. Selected interatomic distances $(\AA)$ : P1-N1 1.7643(14); P1-C1, 1.9025(16); P1-C8, 1.8882(15); N1-N2, 1.2341(18); and 
N2-N3, 1.1325(19). Selected interatomic bond angles $\left(^{\circ}\right)$ : C1-P1-C8, 80.15(7); P1-N1-N2, 115.22(11). B: Explosive decomposition of $\mathrm{N}_{3} \mathrm{PA}$ followed by molecular beam mass spectrometry (MBMS).

A melting point of $\mathrm{N}_{3} \mathrm{PA}$ could not be determined because an explosion occurred at $68^{\circ} \mathrm{C}$. This is in line with the results of our molecular-beam mass spectrometer (MBMS) experiment (Figure 2B); $\mathrm{N}_{3} \mathrm{PA}$ was heated under vacuum and the released molecules analyzed by mass spectrometry. We observed a strong increase in signals for PN $(m / z=45), \mathrm{N}_{2}(m / z=28)$ and A $\left(m / z=178\right.$ and smaller fragments) already at around $42{ }^{\circ} \mathrm{C}$ in the chromatogram as a single strong peak that is clear evidence for an explosive decomposition. Gaseous PN is reported to polymerize very easily and form white powder coatings on surfaces and spectroscopic windows. ${ }^{30}$ We assume that the polymerization process might also contribute significantly to the observed explosion in our melting point determination. The surface of the sealed capillary was also covered with a white powder coating after the explosion occurred. Phosphorus triazide $\left(\mathrm{P}\left(\mathrm{N}_{3}\right)_{3}\right)$ was reported to decompose smoothly in solution at room temperature with liberation of nitrogen, accompanied by the appearance of a strong ${ }^{31} \mathrm{P}$ resonance at $\delta 16.2 \mathrm{ppm}$ and a weaker one at $\delta 6.2 \mathrm{ppm}^{31,32}$ However, these two signals were not assigned at all but an assignment to the free PN molecule could be excluded. Similar to many other reported P(III) azides, $\mathrm{N}_{3} \mathrm{PA}$ decomposes smoothly in solution at room temperature under standard conditions. ${ }^{33}$ Consequently, we followed the decay of $\mathrm{N}_{3} \mathrm{PA}$ in benzene- $d_{6}$ by ${ }^{1} \mathrm{H}$ NMR spectroscopy (Figure S21-S23, Table S1-S2). The azide decomposes at $25.0{ }^{\circ} \mathrm{C}$ with a first order kinetics half-life of around half an hour $\left(t_{1 / 2}=29.1 \pm 1.6 \mathrm{~min}\right)$ and no new resonances appear in the ${ }^{31} \mathrm{P}$ NMR spectrum. Instead we observed the formation of yellow-orange-brown material in our NMR tube that is line with previously reported PN polymerization products; note that the color of the polymer changes depending on the nitrogen content. ${ }^{4,34}$ Further kinetic measurements on $\mathrm{N}_{3} \mathrm{PA}$ decomposition were performed over the temperature range of 25 $55^{\circ} \mathrm{C}$. An Eyring analysis revealed activation parameters of $\Delta H^{\ddagger}=19.5 \pm 1.7 \mathrm{kcal} \mathrm{mol}^{-1}$ and $\Delta S^{\ddagger}=-8.8 \pm 0.8 \mathrm{cal} \mathrm{mol}^{-1} \mathrm{~K}^{-1}$ (Figure S24). The first-order behavior is indicative of a unimolecular rate-determining step, consistent with fragmentation of $\mathrm{N}_{3} \mathrm{PA}$ into $\mathrm{N}_{2}, \mathrm{PN}$ and $\mathbf{A}$.

We computed the most essential part of the potential energy surface around $\mathrm{N}_{3} \mathrm{PA}$ at PBE0-D3(BJ)/cc-pVTZ + Gibbs free energy correction with augmented DLPNO-CCSD(T)/cc-pVTZ single point energies (Figure 3). We located two minima for $\mathrm{N}_{3} \mathrm{PA}$, and the energetically preferred conformer is in line with our crystal structure depicted in Figure $2 \mathrm{~A}$. In the higher energy conformer the $\mathrm{P}-\mathrm{N}$ single bond is rotated by $180^{\circ}$ and the azide group takes a parallel position to a terminal aromatic ring that results in an energy rise of $0.9 \mathrm{kcal} \mathrm{mol}^{-1}$. Both conformers are connected by a low lying transition state TS3 $\left(2.9 \mathrm{kcal} \mathrm{mol}^{-1}\right)$. For the decomposition of $\mathrm{N}_{3} \mathrm{PA}$, two fragmentation pathways have been considered, first: cleavage of dinitrogen from the azide group and the formation of phosphinonitrene ${ }^{35}$ NPA (TS4 $23.3 \mathrm{kcal} \mathrm{mol}^{-1}$ and TS5 $39.8 \mathrm{kcal} \mathrm{mol}^{-1}$ ) that easily further dissociates into $\mathrm{N}_{2}, \mathrm{PN}$ and A via TS6 $\left(1.7 \mathrm{kcal} \mathrm{mol}^{-1}\right)$. The second pathway is connected with the cleavage of anthracene. In an initial step a phosphirane intermediate (I1) forms via TS2 $\left(33.9 \mathrm{kcal} \mathrm{mol}^{-1}\right)$ that further dissociates into $\mathrm{N}_{2}, \mathrm{PN}$ and A via TS1 (42.5 $\left.\mathrm{kcal} \mathrm{mol}^{-1}\right)$. Based on the computed free energy values the first pathway with an initial cleavage of dinitrogen is energetically favored. The minimum energy decomposition pathway with a total barrier of $23.3 \mathrm{kcal} \mathrm{mol}^{-1}$ is within the experimental error of our Eyring analysis $\left(\Delta G^{\ddagger}=\Delta H^{\ddagger}-T \Delta S^{\ddagger}=\right.$ $22.1 \pm 1.5 \mathrm{kcal} \mathrm{mol}^{-1}$ at $\left.298.15 \mathrm{~K}\right)$. 


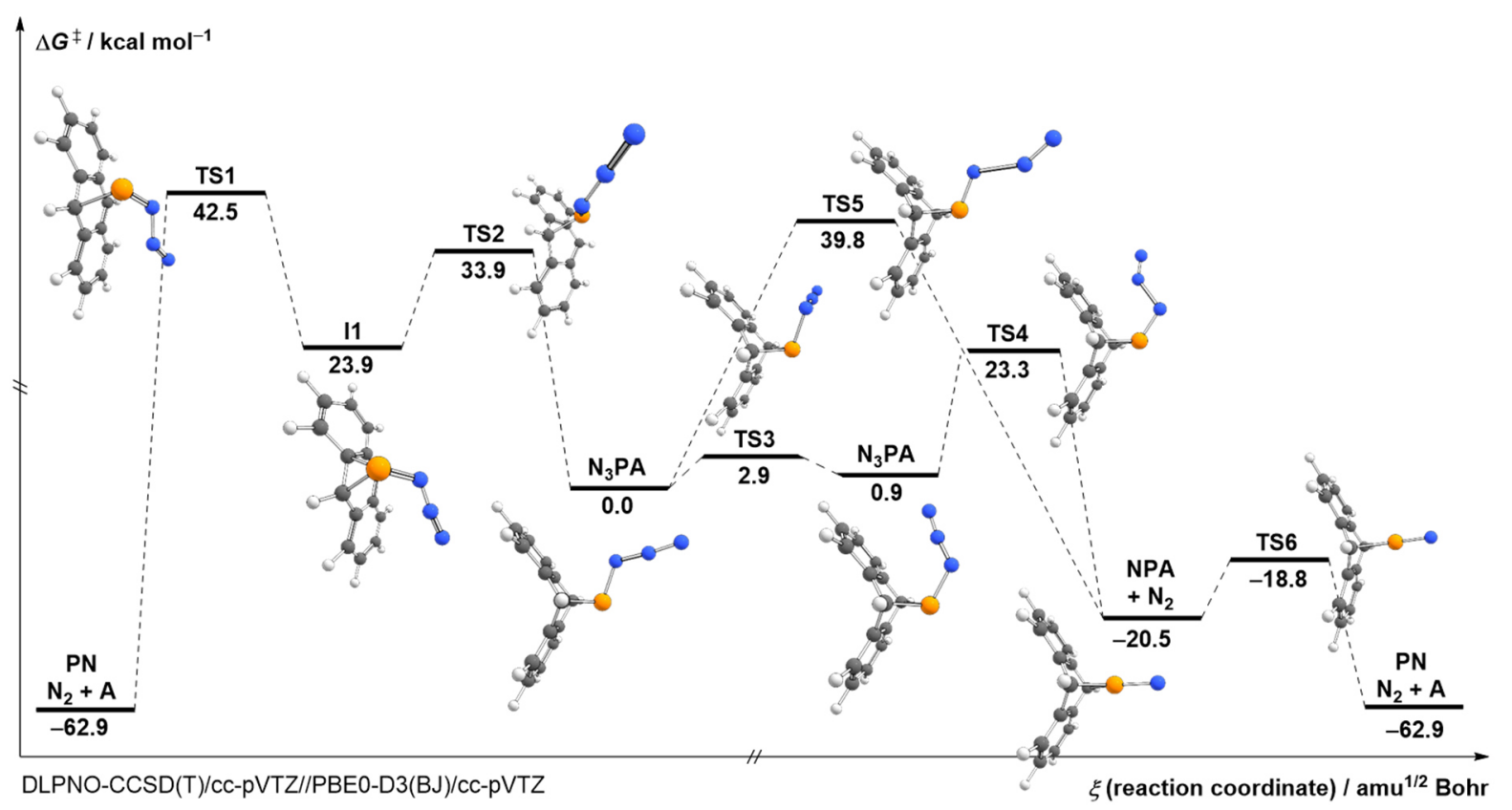

Figure 3 Computed decomposition pathways of $\mathrm{N}_{3}$ PA. $\mathrm{N}_{3} \mathrm{PA}$ decomposes into $\mathrm{N}_{2}$, PN and anthracene either by dinitrogen and subsequent anthracene loss or via a rearrangement to a phosphirane intermediate (I1) and subsequent concerted dissociation into $\mathrm{N}_{2}, \mathrm{PN}$ and anthracene. Gibbs free energy values are computed for $T=298.15$ K. Color code: carbon $=$ grey, hydrogen $=$ white, nitrogen $=$ blue, phosphorus $=$ orange.

Next we focused on the ability of $\mathrm{N}_{3}$ PA to transfer a PN molecule as a ligand to a transition metal complex. As indicated by our computations (vide supra) the $\mathrm{N}_{3} \mathrm{PA}$ molecule has two reactive sites. The reaction may be initiated by cleavage of the azide unit in a Staudinger-type reaction $^{36}$ with dinitrogen release and the remaining NPA unit might be transferred to a transition metal. On the other hand the Cummins group has already demonstrated phosphinidene transfer reactivity of various RPA compounds (including $\mathrm{R}=\mathrm{Me}_{2} \mathrm{~N}, \mathrm{Et}_{2} \mathrm{~N}$, $\left.\mathrm{Me}_{2} \mathrm{Pip},{ }^{i} \mathrm{Pr}_{2} \mathrm{~N}\right){ }^{37}$ Inspired by the recent work of Hamon et al. ${ }^{38}$ we synthesized [(dppe) $\left.\mathrm{Fe}\left(\mathrm{Cp}^{*}\right)\left(\mathrm{N}_{2}\right)\right]\left[\mathrm{BArF}_{24}\right]\left(\mathbf{F e N}_{2}\right.$, dppe $=1$,2-bis(diphenylphosphino)ethane, $\mathrm{Cp}^{*}=1,2,3$, 4,5-pentamethylcyclopentadienyl, $\mathrm{BArF}_{24}=$ Tetrakis[3,5-bis(trifluoromethyl)phenyl]borate) by treatment of (dppe) $\mathrm{Fe}\left(\mathrm{Cp}^{*}\right)(\mathrm{Cl})$ with $\mathrm{NaBArF}_{24}$. After stirring the latter two reagents for 60 min in diethyl ether, the initially dark brown solution turned red and a colorless precipitate $(\mathrm{NaCl})$ developed. After filtration through Celite and layering the filtrate with pentane, dark red crystalline blocks formed after one day (Figure S12). FeN 2 was characterized by IR, NMR, and Mößbauer spectroscopy as well as single crystal X-ray crystallography (vide infra, Figure 4A, S7-S11, S25 and Table S4). We found a nitrogen-nitrogen bond length of 1.131(7) A within the single crystal that is only slightly longer than the dinitrogen triple bond in the gas phase $(1.09768(5) \AA) .{ }^{39}$

Treatment of $\mathbf{F e N}_{2}$ with an excess of $\mathrm{N}_{3} \mathrm{PA}$ ( $\sim 3$ equiv.) at room temperature in diethyl ether immediately led to a gas evolution and precipitation of anthracene as a colorless solid. After filtration the filtrate was placed in the freezer to crystallize further $\mathbf{A}$ that was removed by filtration. The filtrate was layered with pentane. After one day at room temperature dark red crystalline blocks (Figure S20) were observed that were analyzed by IR, NMR, and Mößbauer spectroscopy as well as single crystal X-ray crystallography (vide infra, Figure 4B, S13-S17, S26 and Table S5). Our X-ray crystallographic study revealed the successful formation of [(dppe)Fe( $\left.\left(\mathrm{Cp}^{*}\right)(\mathrm{NP})\right]\left[\mathrm{BArF}_{24}\right](\mathbf{F e N P})$ with the previously weak $\mathrm{N}_{2}$ ligand replaced by PN (Figure 4B). Surprisingly, the PN ligand is terminally N-bonded to the iron center and displays 
a PN bond length of 1.493(2) $\AA$ that is only slightly longer than in free gaseous PN (1.49086(2) $\AA$, vide supra). This is indicative of a weak interaction between the ligand and the metal as also demonstrated in our theoretical analysis (vide infra). Intrinsic bond orbital (IBO) ${ }^{40}$ analysis reveals a Wiberg bond order of 2.51 for the PN ligand, which is minimally perturbed vis-a-vis the free PN molecule. The P-N bond distance in FeNP is longer than in in crystalline $\left[\mathrm{Mes}^{*} \mathrm{NP}\right]^{+}$salts $\left(\mathrm{Mes}^{*}=2,4,6-{ }^{t} \mathrm{Bu}_{3} \mathrm{C}_{6} \mathrm{H}_{2}\right)$, e.g., $1.475(8) \AA$ in 1 or $1.467(4)$ in [Mes*NP][OTf] $\left(\mathrm{OTf}=\mathrm{CF}_{3} \mathrm{SO}_{3}{ }^{-}\right){ }^{18,41}$ In comparison to $[\mathbf{M o}](\mathbf{P N})^{-}$the PN distance is approximately $0.043 \AA$ shorter. ${ }^{14}$ The Wiberg bond order for PN in $[\mathbf{M o}](\mathbf{P N})^{-}$is 2.13 . IBO charges reveal an almost neutral PN ligand in FeNP (N: -0.57, P: 0.57) in stark contrast to $[\mathbf{M o}](\mathbf{P N})^{-}$where the PN ligand carries an overall significant negative charge $(\mathrm{N}:-0.95, \mathrm{P}: 0.57)$. This is consistent with the latter system having considerably more back-bonding to the PN ligand (c.f. Figure 5 and S31).

The diamagnetic nature of the two prepared transition metal complexes allowed us further spectroscopic characterization by multinuclear NMR spectroscopy. The singlet signal at $\delta 85$ ppm in the ${ }^{31} \mathrm{P}\left\{{ }^{1} \mathrm{H}\right\}$ spectrum of the dppe ligand in $\mathbf{F e N}_{2}$ (Figure $4 \mathrm{C}$ left, S9) is split into a doublet in FeNP and slightly shifted downfield to $\delta 86 \mathrm{ppm}$ (Figure 4C right, S15). In addition, a triplet resonance is observed for the NP ligand at $\delta 271 \mathrm{ppm}$ with a coupling constant of ${ }^{3} J_{\mathrm{PP}}=9.2 \mathrm{~Hz}$. We synthesized $50 \%$ enriched $\mathbf{F e}^{\mathbf{1 4 / 1 5}} \mathbf{N P}$ by treatment of $\mathbf{F e N}_{\mathbf{2}}$ with ${ }^{15} \mathrm{~N}$ labeled ${ }^{15} \mathbf{N}_{3} \mathbf{P A}$ (vide supra). In the $\sim 50 \%{ }^{15} \mathrm{~N}$ isotopically enriched $\mathbf{F e} \mathbf{e}^{\mathbf{1 4} / 15} \mathbf{N P}$ complex the triplet resonance at at $\delta 271 \mathrm{ppm}$ splits into a doublet of triplets, partially overlapping with the unlabeled triplet (Figure S18). A weak doublet at $\delta 450 \mathrm{pm}\left({ }^{1} J_{\mathrm{NP}}=51.1 \mathrm{~Hz}\right)$ is observed in the ${ }^{15} \mathrm{~N}$ NMR spectrum (Figure S19). Our attempts to determine the ${ }^{31} \mathrm{P}_{-}{ }^{57} \mathrm{Fe}$ coupling constant between the PN ligand and the iron center failed. We were only able to determine the coupling constant of the dppe ligand to the ${ }^{57} \mathrm{Fe}$ center to be ${ }^{1} J_{\mathrm{FeP}}=55.4 \mathrm{~Hz}$ in $\mathbf{F e N}_{2}$ (Figure S11) and ${ }^{1} J_{\mathrm{FeP}}=56.5 \mathrm{~Hz}$ in FeNP (Figure S17).

We collected solid-state infrared (IR) data of all three crystallized complexes (Figure 4C middle) and observed a strong sharp band at $2116.3 \mathrm{~cm}^{-1}$ in $\mathbf{F e N} 2$ that is characteristic for a $v_{\mathrm{NN}}$ stretching vibration. The band is not present for the FeNP complex. The high wavenumber of $2116.3 \mathrm{~cm}^{-1}$ in comparison to other transition metal dinitrogen complexes is indicative for a weak Fe-N bond. ${ }^{42}$ For FeNP we observed a shoulder signal at $1270.7 \mathrm{~cm}^{-1}$ that is overlapping with another signal but clearly not present in $\mathbf{F e N}_{2}$. We assign this signal to the $v_{\mathrm{NP}}$ stretching mode that is red shifted by roughly $\Delta v=52 \mathrm{~cm}^{-1}$ in comparison to free $\mathrm{PN}\left(v_{\mathrm{NP}}=1323 \mathrm{~cm}^{-1}\right) .5$, 30 A new band appeared for isotopically labeled $\mathbf{F e} \mathbf{e}^{\mathbf{1 5}} \mathbf{N P}$ at $1238.3 \mathrm{~cm}^{-1}$. The experimental isotope shift for the $v_{\mathrm{NP}}$ stretching vibration is $\Delta v_{\mathrm{exp}}=32.4 \mathrm{~cm}^{-1}$ that is in good agreement with a computed harmonic shift of $\Delta v_{\text {calc }}=34.6 \mathrm{~cm}^{-1}$ at the PBE0-D3(BJ)/cc-pVTZ level of theory. 


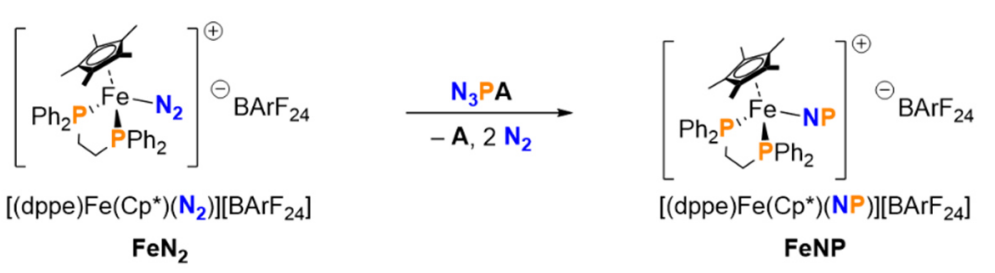

A

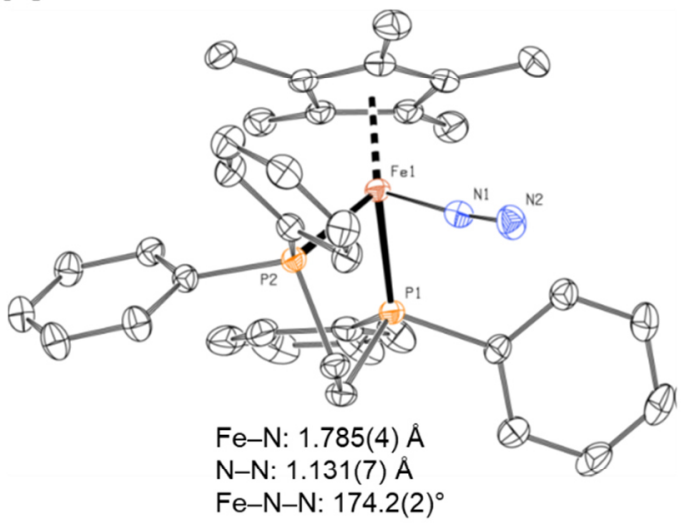

B

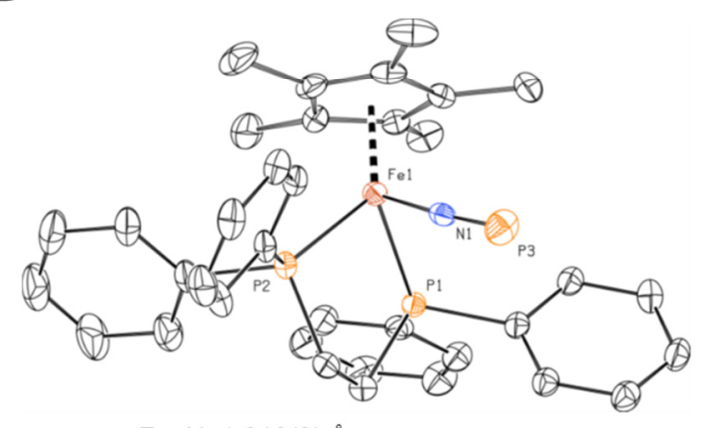

Fe-N: $1.818(2) \AA$

N-P: $1.493(2) \AA$

Fe-N-P: $175.70(13)^{\circ}$
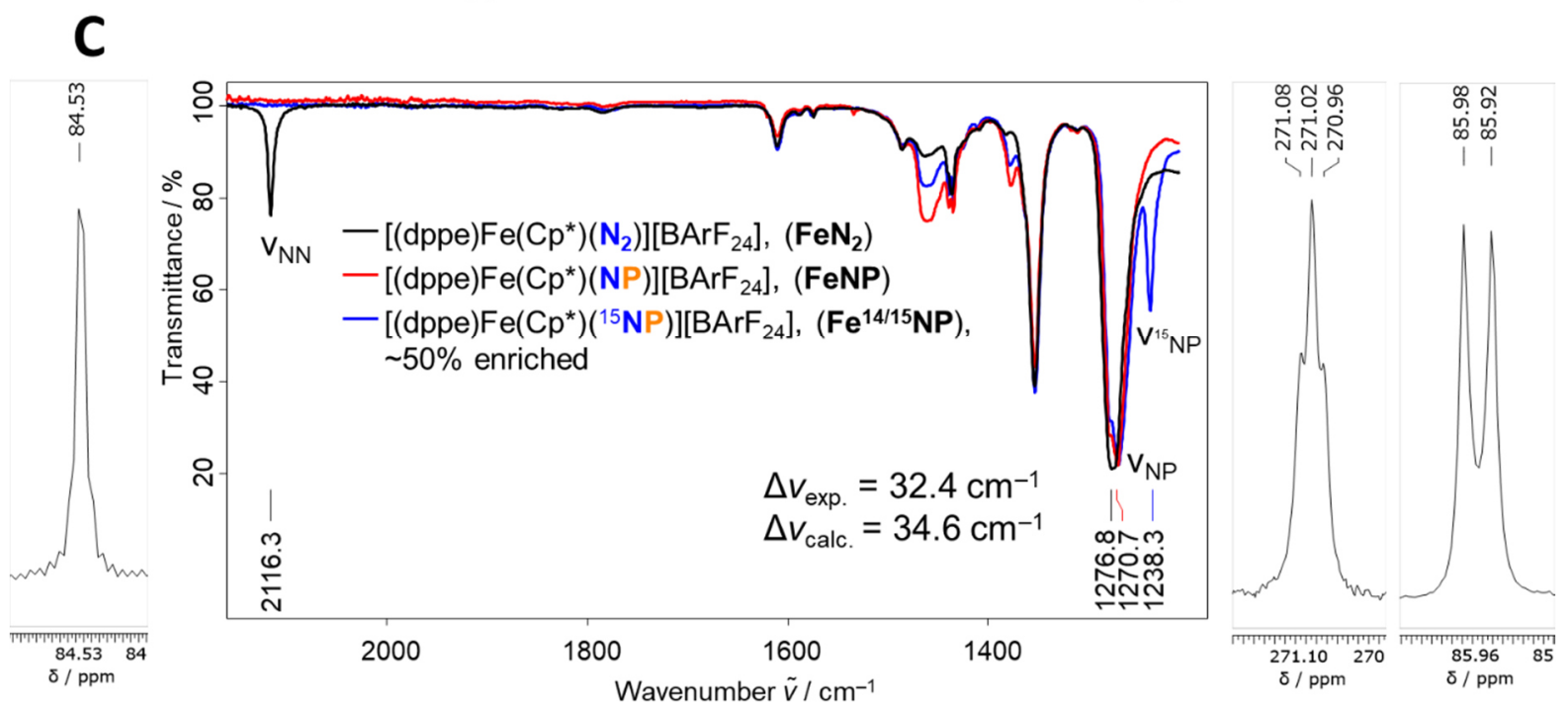

Figure 4 | Synthesis, structure and spectroscopic characterization of FeN2 and FeNP. Top: Synthesis of FeNP. A: Molecular structure of $\mathbf{F e N} \mathbf{N}_{2}$ with thermal ellipsoids shown at the $50 \%$ probability level. Hydrogen atoms are omitted for the sake of clarity. B: Molecular structure of FeNP with thermal ellipsoids shown at the $50 \%$ probability level. Hydrogen atoms are omitted for the sake of clarity. C: Middle: Infrared spectrum of $\mathbf{F e N} 2$ (black), FeNP (red) and $\mathbf{F e}{ }^{14 / 15} \mathbf{N P}$ (blue, $\sim 50 \%$ enriched with ${ }^{15} \mathrm{~N}$ ); left and right ${ }^{31} \mathrm{P}\left\{{ }^{1} \mathrm{H}\right\}$ NMR spectrum of $\mathbf{F e N} \mathbf{N}_{2}$ and FeNP, respectively.

We recorded ${ }^{57} \mathrm{Fe}$ Mößbauer spectra of $\mathbf{F e N}_{\mathbf{2}}$ and $\mathbf{F e N P}$ at $80 \mathrm{~K}$ and fitted the data with two Lorentzian functions as included in the WMOSS software (Figure S25 and S26). ${ }^{43}$ The spectra of the two complexes show a single doublet which clearly establishes the spectroscopic purity of the samples in line with our other analytical characterization methods (see elemental analysis in Methods section). The line broadening of both complexes $\left(\Gamma=0.266 \mathrm{~mm} \mathrm{~s}^{-1}\right.$ for $\mathbf{F e N}_{2}$ and $\Gamma=0.269 \mathrm{~mm} \mathrm{~s}^{-1}$ for FeNP) is similar to the previously reported $\left[(\mathrm{dppe}) \mathrm{Fe}\left(\mathrm{Cp}^{*}\right)\right]\left[\mathrm{PF}_{6}\right]$ complex $\left(\Gamma=0.257 \mathrm{~mm} \mathrm{~s}^{-1}\right){ }^{38}$ The isomer $\operatorname{shift}(\delta)$ for $\mathbf{F e N} \mathbf{N}_{2}$ is $\delta=0.395 \mathrm{~mm} \mathrm{~s}^{-1}$ and for $\mathbf{F e N P}$ is $\delta=0.299 \mathrm{~mm} \mathrm{~s}^{-1}$. The quadrupole splitting $\left(\Delta \mathrm{E}_{\mathrm{Q}}\right)$ for $\mathbf{F e N}_{2}$ is $\Delta \mathrm{E}_{\mathrm{Q}}=2.018 \mathrm{~mm} \mathrm{~s}^{-1}$ and for FeNP is $\Delta E_{Q}=1.696 \mathrm{~mm} \mathrm{~s}^{-1}$. The experimental values are in good agreement with our calculations of the corresponding cations; $\delta=0.409 \mathrm{~mm} \mathrm{~s}^{-1}$ and $\Delta \mathrm{E}_{\mathrm{Q}}=2.008 \mathrm{~mm} \mathrm{~s}^{-1}$ for $\mathbf{F e N}_{\mathbf{2}}{ }^{+}$ and $\delta=0.317 \mathrm{~mm} \mathrm{~s}^{-1}$ and $\Delta \mathrm{E}_{\mathrm{Q}}=1.712 \mathrm{~mm} \mathrm{~s}^{-1}$ for $\mathbf{F e N P}^{+}$(see SI for further details). The 
experimental difference of roughly $0.1 \mathrm{~mm} \mathrm{~s}^{-1}$ for the isomer shift is a hint for a greater covalency in FeNP. Similar observations have been reported by the Peters group. In the $\left[\mathrm{K}(\text { benzo-15-crown-2 })_{2}\right]\left[\left(\left(\mathrm{Ph}_{2} \mathrm{PCH}_{2} \mathrm{SiMe}_{2}\right)_{3} \mathrm{CH}\right) \mathrm{Fe}(\mathrm{L})\right]$ system the isomer shift for $\mathrm{L}=\mathrm{CO}$ is $0.18 \mathrm{~mm} \mathrm{~s}^{-1}$ lower than that for $\mathrm{L}=\mathrm{N}_{2}$, consistent with stronger $\mathrm{CO} \pi$ backbonding. ${ }^{44}$ Our computed reduced Mulliken $\left(\mathrm{FeN}_{2}{ }^{+}: 0.84, \mathbf{F e N P}^{+}: 0.94\right)$ and Löwdin $\left(\mathbf{F e N}_{2}{ }^{+}: 0.88, \mathbf{F e N P}^{+}\right.$: 0.97) orbital charges show a significant higher charge for the Fe $d_{\mathrm{yz}}$ orbital for the FeNP $\mathbf{N}^{+}$ system. The higher orbital charge is related with the experimentally observed lower isomer shift and stronger $\pi$ backbonding in FeNP (vide infra).

We explored the potential energy surface around FeNP computationally. As a global energetic minimum we located a closed shell $(S=0$, with $S$ as the total spin number of the system) low spin electronic ground state for the $\left[(\mathrm{dppe}) \mathrm{Fe}\left(\mathrm{Cp}^{*}\right)(\mathrm{NP})\right]^{+}$cation $\left(\mathbf{F e N P}^{+}\right)$at the DLPNO-CCSD(T)/cc-pVTZ//PBE0-D3(BJ)/cc-pVTZ + thermal correction to Gibbs free energy level of theory (Figure 5). Isomerization of the NP ligand occurs via the side-on bound isomer that is connected via TS1 (25.5 kcal mol ${ }^{-1}$, Figure 5) to $\mathbf{F e N P}^{+}$and $16.8 \mathrm{kcal} \mathrm{mol}^{-1}$ energetically less preferred. Further isomerization via TS2 (36.6 kcal mol ${ }^{-1}$, Figure 5) leads to the PN linkage isomer $\mathbf{F e P N}{ }^{+}$that is surprisingly $14.3 \mathrm{kcal} \mathrm{mol}^{-1}$ higher in energy than the FeNP $^{+}$isomer. We computed the ${ }^{31} \mathrm{P}$ NMR chemical shifts of all three isomers according to a literature benchmark study at the PBE0-D3(BJ)/6-31G(d) level of theory. ${ }^{45}$ According to the computations all three isomers should be distinguishable by NMR spectroscopy as they are separated by roughly $80 \mathrm{ppm}$ (Figure 5). The computed chemical shift for $\mathbf{F e N P}^{+}$with $\delta 282 \mathrm{ppm}$ is in good agreement with the experimentally observed resonance at $\delta 271 \mathrm{ppm}$. The energetic high barrier of TS2 $\left(36.6 \mathrm{kcal} \mathrm{mol}^{-1}\right)$ prevents isomerization of the NP ligand at room temperature. Even after refluxing the complex in toluene or after irradiation with green and yellow light with light emitting diodes (LEDs) we did not observe any new resonance by ${ }^{31} \mathrm{P}$ NMR spectroscopy.

The energetic preference of the $\mathbf{F e N P}^{+}$isomer vs the $\mathbf{F e P N}{ }^{+}$is surprising because we initially expected a better orbital overlap between iron and phosphorus and a preference of the $\mathbf{F e P N} \mathbf{P N}^{+}$ isomer. However, our local energy decomposition (LED) ${ }^{46}$ and natural orbital chemical valence $(\mathrm{NOVC})^{47}$ analysis indicates that the interaction between the ligand and the metal center is of significant covalent nature (see Figure 5 top for intrinsic bond orbitals (IBOs) and Figure S27S30 and Table S6-S11). In the NOCV/EDA analysis ${ }^{48}$ of $\mathbf{F e N P}^{+}$we obtain an energy of $90.8 \mathrm{kcal} \mathrm{mol}^{-1}$ (Table S5) for the orbital interaction term $\Delta E_{\text {orb}}$, representing orbital mixing effects, e.g., charge transfer and polarization effects. As the term is similar for $\mathbf{F e P N}{ }^{+}(-98.8$ $\left.\mathrm{kcal} \mathrm{mol}^{-1}\right)$, this is indicative that the interaction between the ligand and the metal center is strongly covalent in nature and mainly dominated by the $\Delta E_{\text {steric }}$ term $\left(44.0 \mathrm{kcal} \mathrm{mol}^{-1}\right.$ for $\mathbf{F e N P}^{+}$and $66.8 \mathrm{kcal} \mathrm{mol}^{-1}$ for $\mathbf{F e P N}{ }^{+}$). The most important mixing contributions for $\mathbf{F e N P} \mathbf{P}^{+}$ is the $\pi$-backdonation from the occupied $d$ orbitals of suitable symmetry on the Fe atom to the empty LUMO antibonding $\pi^{*}$ orbitals of the ligand $\Delta E_{\mathrm{orb}}\left[d(\mathrm{Fe}) \rightarrow \pi^{*}(\mathrm{NP})\right]\left(-28.6 \mathrm{kcal} \mathrm{mol}^{-1}\right.$, Figure S31) and $\Delta E_{\mathrm{orb}}\left[d(\mathrm{Fe}) \rightarrow \pi_{\perp}(\mathrm{NP})\right]\left(-21.9 \mathrm{kcal} \mathrm{mol}^{-1}\right.$, Figure S31). Another significant contribution is the $\sigma$-donation from the HOMO of the ligand to the empty $d$ orbitals of Fe $\Delta E_{\text {orb }}[\sigma(\mathrm{NP}) \rightarrow d(\mathrm{Fe})]\left(-32.1 \mathrm{kcal} \mathrm{mol}^{-1}\right.$, Figure $\left.\mathrm{S} 31\right)$. The relative stability of the isomers correlates well only with Pauli repulsion effects. Thus, the relative stability between the isomers essentially originates from the fact that the atomic orbitals on phosphorus are larger and more diffuse than those on nitrogen. This causes an increase in Pauli repulsion when the ligand coordinates from the phosphorus side. This is not compensated by a corresponding increase in orbital interactions, as quantified by the NOCV scheme (Table S11). With a 
dinitrogen ligand in $\mathbf{F e N}_{2}{ }^{+}$the orbital interactions are qualitatively the same as in $\mathbf{F e N P} \mathbf{P}^{+}$. In general, the frontier orbitals of $\mathrm{N}_{2}$ are of similar shape and nature as in PN (Figure S30). However, the LUMO orbitals of $\mathrm{N}_{2}$ feature higher energies than those of PN, whilst the HOMO and HOMO-1 orbitals show lower energies. Hence, $\mathrm{N}_{2}$ is expected to be a poorer $\pi$ acceptor as well as a poorer $\sigma$ donor than PN. This is confirmed by our NOCV/EDA analysis. All donation and back donation components are smaller in $\mathbf{F e N}_{2}{ }^{+}\left(\Delta E_{\text {orb }}\left[d(\mathrm{Fe}) \rightarrow \pi^{*}\left(\mathrm{~N}_{2}\right)\right]=-22.2\right.$ $\mathrm{kcal} \mathrm{mol}^{-1} ; \Delta E_{\mathrm{orb}}\left[d(\mathrm{Fe}) \rightarrow \pi_{\perp}\left(\mathrm{N}_{2}\right)\right]=-18.1 \mathrm{kcal} \mathrm{mol}^{-1}$ and $\Delta E_{\mathrm{orb}}\left[\sigma\left(\mathrm{N}_{2}\right) \rightarrow d(\mathrm{Fe})\right](-24.1 .1 \mathrm{kcal}$ $\mathrm{mol}^{-1}$ ) than in $\mathbf{F e N P}^{+}$(Table S11). The covalent interaction between the iron center and the PN ligand is also shown by IBO analysis (Figure 5 top). The backbonding of the metal to the ligand is only minimal (see second row right orbital in Figure 5) and in stark contrast to the situation for $[\mathbf{M o}](\mathbf{P N})^{-}$complex reported by the Smith group (Figure S31).

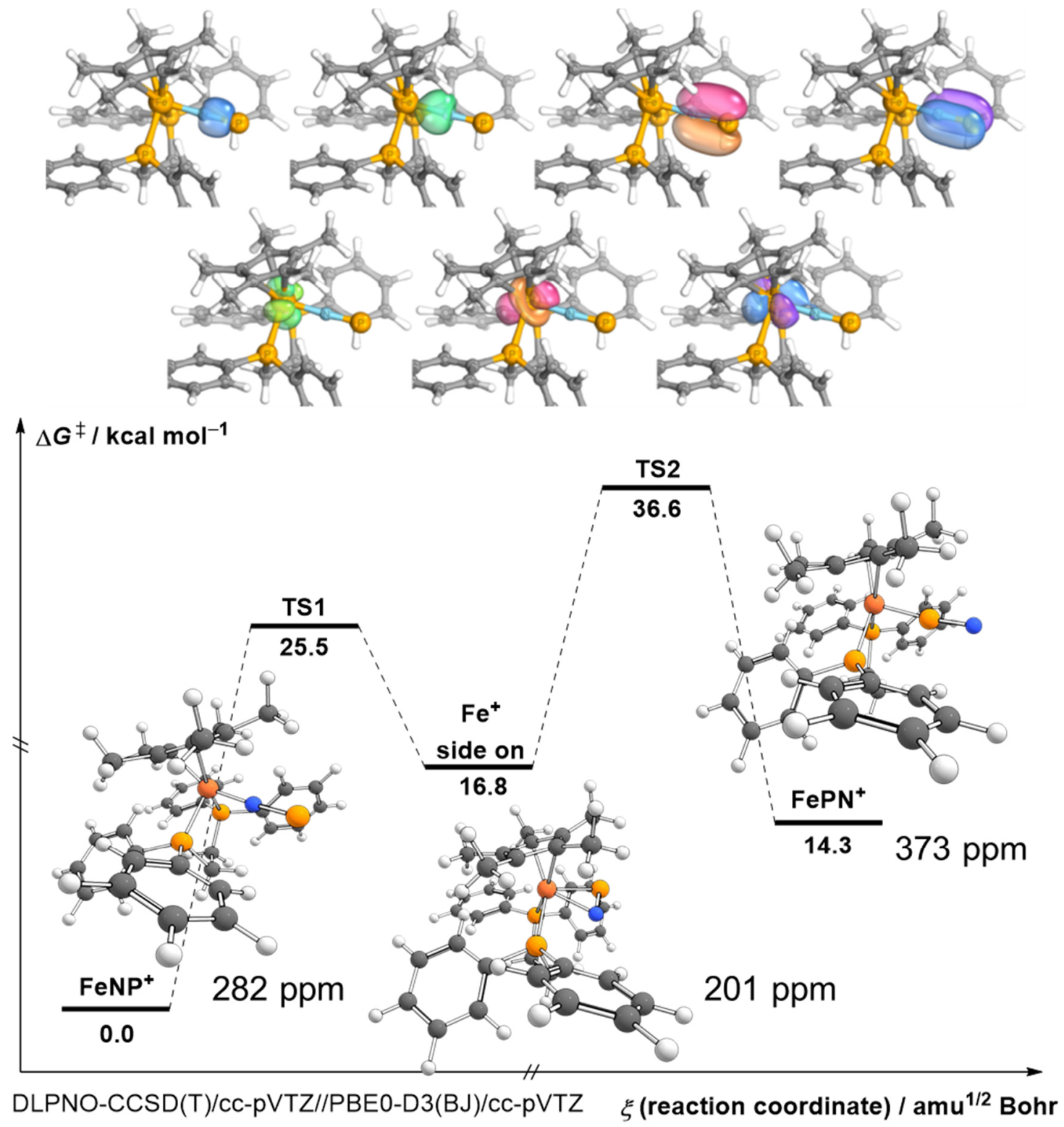

Figure 5 | Isomerization of the PN ligand in $\left[(\mathrm{dppe}) \mathrm{Fe}\left(\mathrm{Cp}^{*}\right)(\mathrm{NP})\right]^{+}$and analysis of the bonding situation. Top: Selected intrinsic bond orbitals (IBOs): The top row shows the $\sigma_{\mathrm{PN}}$, the $\sigma_{\mathrm{FeN}}$, and the two $\pi_{\mathrm{PN}}$ bonds. The bottom row shows the three doubly occupied $d$ orbitals of this $\mathrm{d}^{6}$ complex. Bottom: Potential energy surface for the isomerization of the PN ligand. Color code: carbon $=$ grey, hydrogen $=$ white, nitrogen $=$ blue, phosphorus $=$ orange, iron $=$ brown. 
In summary, we presented the synthesis and development of a molecular precursor $\mathrm{N}_{3} \mathrm{PA}$ that dissociates at room temperature and slowly releases dinitrogen, anthracene and phosphorus mononitride with a half-life of roughly half an hour. Phosphorus mononitride polymerizes very rapidly in solution by forming yellow-orange-brown polymers but can be efficiently transferred and trapped as demonstrated by the synthesis of $\left[(\mathrm{dppe}) \mathrm{Fe}\left(\mathrm{Cp}^{*}\right)(\mathrm{NP})\right][\mathrm{BArF} 24]$. The PN ligand is surprisingly $\mathrm{N}$-bonded to the iron center because of a significant covalent iron pnictogen bond character that results in less Pauli repulsion when the ligand coordinates from the $\mathrm{N}$ side. The synthesis of $\mathrm{N}_{3} \mathrm{PA}$ and the prepared iron complex with a PN ligand opens new pathways to conduct further reactivity studies of the PN molecule in the future.

\section{Methods}

Caution. The handling of azide compounds should be done with the necessary safety precautions. ${ }^{49}$ No direct explosions of $\mathrm{N}_{3} \mathrm{PA}$ were encountered when it was diluted in organic solvents or carefully dried under vacuum below room temperature. Treatment of transition metal complexes in solution with solid $\mathrm{N}_{3} \mathrm{PA}$ can cause a spontaneous explosive decomposition of $\mathrm{N}_{3} \mathrm{PA}$ and should be avoided or solid $\mathrm{N}_{3} \mathrm{PA}$ only be added in portions of a few milligrams, respectively.

All manipulations were performed in a Vacuum Atmospheres model MO-40M glovebox under an inert atmosphere of purified $\mathrm{N}_{2}$. All solvents were obtained anhydrous and oxygen-free by bubble degassing $\left(\mathrm{N}_{2}\right)$ and purification through columns of alumina and Q5, ${ }^{50}$ and storage over molecular sieves. ${ }^{51}$ Literature procedures were followed for the preparation of $\mathrm{MgA} \cdot 3 \mathrm{THF},{ }^{37} \mathrm{Me}_{2} \mathrm{NPA}_{2},{ }^{23} \mathrm{ClPA}^{23}(\mathbf{A}=$ $\mathrm{C}_{14} \mathrm{H}_{10}$, anthracene) and (dppe) $\mathrm{Fe}\left(\mathrm{Cp}^{*}\right)(\mathrm{Cl}){ }^{52,53}$ Dimethylaminophosphorus dichloride $\left(\mathrm{Me}_{2} \mathrm{NPCl}_{2}\right)$ was purchased from Alfa Aesar and used as received. Lithium chloride $(\mathrm{LiCl})$ and sodium azide $\left(\mathrm{NaN}_{3}\right)$ were purchased from Sigma Aldrich and used as received. Deuterated solvents were purchased from Cambridge Isotope Laboratories, degassed, and stored over molecular sieves for at least $48 \mathrm{~h}$ prior to use. Activated Charcoal Norit CA1 (Aldrich) and Celite 435 (EM Science) were dried by heating above $200{ }^{\circ} \mathrm{C}$ under dynamic vacuum for at least $48 \mathrm{~h}$. All glassware was oven dried for at least $3 \mathrm{~h}$ at temperatures greater than $150{ }^{\circ} \mathrm{C}$. NMR spectra were obtained on Bruker Avance 400, 401 or Bruker Neo 500 instruments equipped with Magnex Scientific superconducting magnets. ${ }^{1} \mathrm{H}$ and ${ }^{13} \mathrm{C}$ NMR spectra were referenced to residual protiated solvent resonances; $;{ }^{54} \quad{ }^{31} \mathrm{P}$ NMR spectra were referenced externally to $85 \%$ aqueous $\mathrm{H}_{3} \mathrm{PO}_{4}(\delta=0 \mathrm{ppm})$. Elemental analyses were performed by Midwest Microlab (Indianapolis, IN). High resolution mass spectral (HRMS) data were collected using a Jeol AccuTOF 4G LC-Plus mass spectrometer equipped with an Ion-Sense DART source. Data were calibrated to a sample of PEG-600 and were collected in positive ion mode. Samples were prepared in THF (ca. $10 \mu \mathrm{M}$ concentration) and were briefly exposed to air $(<5 \mathrm{~s})$ before being placed in front of the DART source. Zero-field ${ }^{57} \mathrm{Fe}$ Mößbauer spectra were measured with a constant acceleration spectrometer at $80 \mathrm{~K}$ with isomer shifts reported relative to $\mathrm{Fe}$ foil at $298 \mathrm{~K}\left(0 \mathrm{~mm} \mathrm{~s}^{-1}\right)$; data were analyzed and simulated with WMOSS $\mathrm{v} .{ }^{43}$

Synthesis of $\mathbf{N}_{3}$ PA. Inside the glovebox, a $20 \mathrm{~mL}$ vial was charged with solid, colorless ClPA (500 mg, 2.04 mmol, 1.0 equiv.), $\mathrm{NaN}_{3}$ (675 mg, 10.38 mmol, 5.0 equiv.), $\mathrm{LiCl}$ (180 mg, $4.25 \mathrm{mmol}, 2.0$ equiv.) and a magnetic stir bar. Precooled $\left(-20^{\circ} \mathrm{C}\right)$ THF $(15 \mathrm{~mL})$ was added to the vial that was tightly closed with a cap and subsequently transported to the freezer inside the glovebox where it was stirred in the dark for $7 \mathrm{~d}$ at $-20^{\circ} \mathrm{C}$. After seven days, all volatiles were removed under reduced pressure to yield a cream-colored solid residue. The solids were slurried in diethyl ether $(4 \times 20 \mathrm{~mL})$ at room temperature and filtered through a celite:charcoal $(1: 1,4 \mathrm{~cm})$ plug in a $15 \mathrm{~mL}$ medium frit. The colorless ethereal solution was collected in a filter flask that was precooled in the liquid $\mathrm{N}_{2}$ immersed coldwell of the glovebox. Removal of solvent in vacuo from the colorless filtrate left a colorless solid that was weighed and stored in the freezer. Yields varied depending on how much anthracene was produced during the course of the reaction and the workup, giving up to $360 \mathrm{mg}(70 \%)$ crude product with some anthracene 
impurities that rapidly decomposes at room temperature yielding a yellowish mixture of anthracene and PN polymers. The identity of the product was confirmed by NMR and IR spectroscopy as well as by an $\mathrm{X}$-ray diffraction study performed on a crystal grown from diethyl ether at $-20{ }^{\circ} \mathrm{C}$ (Figure $2 \mathrm{~A}$ ). A melting point for this material could not be determined. At $46.0 \pm 0.5^{\circ} \mathrm{C}$ the compound decomposes in an explosive fashion. DART HRMS(Q-TOF) $m / z$ : $[\mathrm{M}+\mathrm{H}]^{+}$Calcd for $\mathrm{C}_{14} \mathrm{H}_{11} \mathrm{~N}_{3} \mathrm{P} 252.0685$; Found 252.0698. ${ }^{1} \mathrm{H}$ NMR (benzene- $\left.d_{6}, 400 \mathrm{MHz}, 25^{\circ} \mathrm{C}\right) \delta 7.41(\mathrm{~m}, 2 \mathrm{H}), 7.33(\mathrm{~m}, 2 \mathrm{H}), 7.17(\mathrm{~m}, 2 \mathrm{H}), 6.98(\mathrm{~m}$, $2 \mathrm{H}), 4.06\left(\mathrm{~d}, 2 \mathrm{H},{ }^{2} J_{\mathrm{PH}}=12.6 \mathrm{~Hz}, \mathrm{H} 4\right) \mathrm{ppm} .{ }^{13} \mathrm{C}\left\{{ }^{1} \mathrm{H}\right\}$ NMR (benzene- $\left.d_{6}, 126 \mathrm{MHz}, 25{ }^{\circ} \mathrm{C}\right) \delta 145.9(\mathrm{~d}, J$ $=3.1 \mathrm{~Hz}), 141.7(\mathrm{~d}, J=22.5 \mathrm{~Hz}), 126.5,125.2,124.5,123.7(\mathrm{~d}, J=3.5 \mathrm{~Hz}), 56.8(\mathrm{~d}, J=18.9 \mathrm{~Hz}) \mathrm{ppm}$. ${ }^{31} \mathrm{P}\left\{{ }^{1} \mathrm{H}\right\}$ NMR (benzene- $\left.d_{6}, 162 \mathrm{MHz}, 25^{\circ} \mathrm{C}\right) \delta 181 \mathrm{ppm} . \mathrm{X}-{ }^{15} \mathrm{~N}{ }^{31} \mathrm{P}\left\{{ }^{1} \mathrm{H}\right\}$ NMR (benzene- $d_{6}, 162 \mathrm{MHz}$, $\left.25{ }^{\circ} \mathrm{C}\right) \delta 181\left(\mathrm{~d}, J_{\mathrm{PN}}=77.9 \mathrm{~Hz}\right), 181(\mathrm{~s}, \mathrm{~b}) \mathrm{ppm} .{ }^{15} \mathrm{~N}$ NMR (benzene- $\left.d_{6}, 50.7 \mathrm{MHz}, 25^{\circ} \mathrm{C}\right) \delta 310,197$ ppm.

Synthesis of $\left[(\mathbf{d p p e}) \mathbf{F e}\left(\mathbf{C} \mathbf{p}^{*}\right)\left(\mathbf{N}_{2}\right)\right]\left[\mathbf{B A r F} \mathbf{F}_{24}\right]$. To a stirring solution of $100 \mathrm{mg}(0.159 \mathrm{mmol})$ (dppe) $\mathrm{Fe}\left(\mathrm{Cp}^{*}\right) \mathrm{Cl}$ in diethyl ether $(4 \mathrm{~mL})$ was added $141 \mathrm{mg}\left(0.159 \mathrm{mmol}, 1\right.$ equiv.) $\mathrm{NaBArF}_{24}$ portionwise. After stirring for $60 \mathrm{~min}$, the initially dark brown solution became pale red and a precipitate formed. The solution was filtered through Celite and the solvent removed from the filtrate. The red solids were triturated with pentane $(3 \times 2 \mathrm{~mL})$ and dried under vacuum. The solids were dissolved in 2 $\mathrm{mL}$ diethyl ether and layered with $5 \mathrm{~mL}$ pentane to crystallize $\left[(\mathrm{dppe}) \mathrm{Fe}\left(\mathrm{Cp}^{*}\right)\left(\mathrm{N}_{2}\right)\right][\mathrm{BArF} 24]$. After $24 \mathrm{~h}$ at room temperature large dark red blocks formed out of solution. These blocks were analyzed by NMR spectroscopy and in a X-ray diffraction crystallographic study. Yield: $173 \mathrm{mg}(0.116 \mathrm{mmol}, 73 \%)$. Anal. Calcd for $\mathrm{C}_{68} \mathrm{H}_{51} \mathrm{BF}_{24} \mathrm{FeN}_{2} \mathrm{P}_{2}: \mathrm{C}, 55.16 ; \mathrm{H}, 3.47 ; \mathrm{N}, 4.54$. Found: $\mathrm{C}, 54.76 ; \mathrm{H}, 3.84 ; \mathrm{N}, 0.0 .{ }^{1} \mathrm{H}$ NMR (diethyl ether (solvent suppressed), $\left.500 \mathrm{MHz}, 25^{\circ} \mathrm{C}\right) \delta 8.27\left(\mathrm{~m}, 8 \mathrm{H}, \mathrm{BArF}_{24}\right), 8.10(\mathrm{~m}$, found $14 \mathrm{H}$, expected 16H), $8.03(\mathrm{~m}, 4 \mathrm{H}), 7.91\left(\mathrm{~m}, 4 \mathrm{H}, \mathrm{BArF}_{24}\right), 2.96(\mathrm{~m}, 2 \mathrm{H}), 2.81(\mathrm{~m}, 2 \mathrm{H}), 1.92(\mathrm{~s}, 15 \mathrm{H}) \mathrm{ppm}$. ${ }^{13} \mathrm{C}\left\{{ }^{1} \mathrm{H}\right\}$ NMR (diethyl ether, $\left.126 \mathrm{MHz}, 25{ }^{\circ} \mathrm{C}\right) \delta 162.1(\mathrm{q}, J=50.0 \mathrm{~Hz}), 135.1(\mathrm{~m}), 133.7(\mathrm{~m}), 132.6$ (m), 13.6 (d, $J=29.6 \mathrm{~Hz}), 130.9(\mathrm{~m}), 129.6(\mathrm{~m}), 125.0$ (q, $J=272.0 \mathrm{~Hz}), 117.5(\mathrm{~m}), 92.2,28.7,9.0 \mathrm{ppm}$. ${ }^{31} \mathrm{P}\left\{{ }^{1} \mathrm{H}\right\}$ NMR (diethyl ether, solvent suppressed, $203 \mathrm{MHz}, 25{ }^{\circ} \mathrm{C}$ ) $85 \mathrm{ppm}$. IR (ATR, crystals covered with oil under air): $2117 \mathrm{~cm}^{-1}\left(v_{\mathrm{NN}}\right)$.

Synthesis of [(dppe)Fe(Cp*)(NP)][BArF $\left.{ }_{24}\right]$. Inside the glovebox, to a stirring solution of $55 \mathrm{mg}(0.037$ mmol) [(dppe) $\left.\mathrm{Fe}\left(\mathrm{Cp}^{*}\right)\left(\mathrm{N}_{2}\right)\right]\left[\mathrm{BArF}_{24}\right]$ in diethyl ether $(5 \mathrm{~mL})$ was added carefully $37 \mathrm{mg}(0.148 \mathrm{mmol}$, $\sim 4$ equiv.) $\mathrm{N}_{3} \mathrm{PA}$ portionwise. Gas evolution occured immediately and a precipitate (anthracene) develops. The solution was filtered after stirring for $15 \mathrm{~min}$ and placed in the freezer for $2 \mathrm{~h}$ to crystallize out any further anthracene. After two hours anthracene was filtered off and the resulting solution layered with $5 \mathrm{~mL}$ pentane to crystallize [(dppe) $\left.\mathrm{Fe}\left(\mathrm{Cp}^{*}\right)(\mathrm{NP})\right]\left[\mathrm{BArF}_{24}\right]$. After $24 \mathrm{~h}$ at room temperature large dark red blocks formed out of solution. These blocks were analyzed by NMR spectroscopy and in a Xray diffraction crystallographic study. Yield: $40 \mathrm{mg}(0.027 \mathrm{mmol}, 73 \%)$. Anal. Calcd for $\mathrm{C}_{68} \mathrm{H}_{51} \mathrm{BF}_{24} \mathrm{FeNP}_{3}$ : C, 54.53; H, 3.43; N, 0.94. Found: $\mathrm{C}, 54.20 ; \mathrm{H}, 3.55 ; \mathrm{N}, 0.34$. ${ }^{1} \mathrm{H}$ NMR (diethyl ether (solvent suppressed), $\left.400 \mathrm{MHz}, 25^{\circ} \mathrm{C}\right) \delta 8.43\left(\mathrm{~m}\right.$, found $9 \mathrm{H}$, expected $\left.8 \mathrm{H}, \mathrm{BArF}_{24}\right), 8.20(\mathrm{~m}, 20 \mathrm{H}), 8.01$ (m, 4H, BArF 24$), 3.31(\mathrm{~m}, 2 \mathrm{H}), 3.01(\mathrm{~m}, 2 \mathrm{H}), 1.98(\mathrm{~s}, 15 \mathrm{H}) \mathrm{ppm} .{ }^{13} \mathrm{C}\left\{{ }^{1} \mathrm{H}\right\}$ NMR (diethyl ether, 126 $\left.\mathrm{MHz}, 25^{\circ} \mathrm{C}\right) \delta 162.2\left(\mathrm{q}, J=50.0 \mathrm{~Hz}, \mathrm{BArF}_{24}\right), 135.3\left(\mathrm{~s}(\mathrm{~b}), \mathrm{BArF}_{24}\right), 133.8(\mathrm{~m}), 133.6(\mathrm{~m}), 132.7(\mathrm{~d}, J$ $=29.6 \mathrm{~Hz}), 129.8\left(\mathrm{~m}, \mathrm{BArF}_{24}\right), 129.5(\mathrm{~m}), 125.2\left(\mathrm{q}, J=272.0 \mathrm{~Hz}, \mathrm{BArF}_{24}\right), 117.7,94.7,28.1(\mathrm{~m}), 9.0$ (d, $J=29.6 \mathrm{~Hz}$ ppm. ${ }^{31} \mathrm{P}\left\{{ }^{1} \mathrm{H}\right\}$ NMR (diethyl ether, solvent suppressed, $\left.203 \mathrm{MHz}, 25^{\circ} \mathrm{C}\right) 271(\mathrm{t}, J=$ 9.2), $86(\mathrm{~d}, J=8.8) \mathrm{ppm} .{ }^{15} \mathrm{~N}$ enriched sample: ${ }^{31} \mathrm{P}\left\{{ }^{1} \mathrm{H}\right\}$ NMR (diethyl ether, solvent suppressed, 203 $\left.\mathrm{MHz}, 25^{\circ} \mathrm{C}\right) 271\left(\mathrm{dt}, J_{\mathrm{PN}}=53.4, J_{\mathrm{PP}}=9.5\right), 86\left(\mathrm{~d}, J_{\mathrm{PP}}=8.5\right) \mathrm{ppm} .{ }^{15} \mathrm{~N}$ NMR (diethyl ether, solvent suppressed, $\left.50.7 \mathrm{MHz}, 25^{\circ} \mathrm{C}\right) \delta 450\left(\mathrm{~d}, J_{\mathrm{PN}}=51.1\right) \mathrm{ppm}$. 


\section{Data Availability}

All relevant data generated and analyzed during this study, including crystal structures, NMR, IR, MBMS spectra and optimized coordinates for all calculated compounds, are included in this Article and its Supplementary Information, and are also available from the authors upon reasonable request.

\section{Acknowledgements}

A.K.E. thanks the Alexander von Humboldt foundation for a Feodor Lynen postdoctoral fellowship. This material is based on research supported by the National Science Foundation, under No. CHE-1955612. We thank all MIT DCIF staff members and Dr. Clemens Anklin (Bruker) for technical support with NMR measurements, as well as Michael C. McCarthy (Harvard CfA), Robert J. Gilliard (University of Virginia) and Daniel L.M. Suess (MIT) for fruitful discussion.

\section{Author contributions}

A.K.E. conducted all experiments, carried out the computations of the potential energy surfaces and analyzed the data. M.-L.Y.R. and P.M. collected all diffraction data and refined the structures. M.Y. collected all Mößbauer data. G.B. analyzed the bonding situation in $\left[(\mathrm{dppe}) \mathrm{Fe}\left(\mathrm{Cp}^{*}\right)(\mathrm{NP})\right]\left[\mathrm{BArF}_{24}\right]$. C.C.C. administrated the study. A.K.E. wrote the manuscript with input from all authors.

\section{Competing financial interests}

None.

\section{Materials \& Correspondence}

Correspondence and material requests should be addressed to C.C.C.

\section{Orcid}

A.K.E. 0000-0003-1029-9272

M.L.Y.R. 0000-0002-0900-3545

M.Y. 0000-0003-2709-8135

P.M. 0000-0001-6530-3852

G.B. 0000-0003-4849-1323

C.C.C. $0000-0003-2568-3269$

\section{References}

1. Ziurys L. Detection of interstellar PN-the first phosphorus-bearing species observed in molecular clouds. Astrophys. J. 321, L81-L85 (1987). 
2. Turner B, Bally J. Detection of interstellar PN-The first identified phosphorus compound in the interstellar medium. Astrophys. J. 321, L75-L79 (1987).

3. Curry J, Herzberg L, Herzberg G. Spectroscopic Evidence for the Molecule PN. J. Chem. Phys. 1, 749-749 (1933).

4. Moldenhauer W, Dörsam H. Über die Vereinigung von Phosphor und Stickstoff unter dem Einflusse elektrischer Entladungen. Ber. dtsch. Chem. Ges. A/B 59, 926-931 (1926).

5. Atkins RM, Timms PL. The matrix infrared spectrum of PN and SiS. Spectrochim. Acta, Part A 33, 853-857 (1977).

6. Zhu C, Bergantini A, Singh SK, Kaiser RI, Eckhardt AK, Schreiner PR, et al. Formation of phosphine imide $\left(\mathrm{HN}=\mathrm{PH}_{3}\right)$ and its phosphinous amide $\left(\mathrm{H}_{2} \mathrm{~N}-\mathrm{PH}_{2}\right)$ isomer. Chem. Commun. 57, 4958-4961 (2021).

7. Zhu C, Eckhardt AK, Bergantini A, Singh SK, Schreiner PR, Kaiser RI. The elusive cyclotriphosphazene molecule and its Dewar benzene-type valence isomer $\left(\mathrm{P}_{3} \mathrm{~N}_{3}\right) . S c i . A d v . \mathbf{6}$, eaba6934 (2020).

8. Atkins RM, Timms PL. Interaction of PN with metal atoms in a krypton matrix. Inorg. Nucl. Chem. Letters 14, 113-115 (1978).

9. Ahlrichs R, Bär M, Plitt HS, Schnöckel H. The stability of PN and $(\mathrm{PN})_{3}$. Ab initio calculations and matrix infrared investigations. Chem. Phys. Lett. 161, 179-184 (1989).

10. Göbel M, Karaghiosoff K, Klapötke TM. The First Structural Characterization of a Binary P$\mathrm{N}$ Molecule: The Highly Energetic Compound $\mathrm{P}_{3} \mathrm{~N}_{21}$. Angew. Chem. Int. Ed. 45, 6037-6040 (2006).

11. McSkimming A, Suess DLM. Dinitrogen binding and activation at a molybdenum-iron-sulfur cluster. Nat. Chem. 13, 666-670 (2021).

12. Sun J, Verplancke H, Schweizer JI, Diefenbach M, Würtele C, Otte M, et al. Stabilizing $\mathrm{P} \equiv \mathrm{P}$ : $\mathrm{P}_{2}{ }^{2-}, \mathrm{P}_{2}{ }^{-}$, and $\mathrm{P}_{2}{ }^{0}$ as bridging ligands. Chem 7, 1952-1962 (2021).

13. Du J, Hunger D, Seed JA, Cryer JD, King DM, Wooles AJ, et al. Dipnictogen f-Element Chemistry: A Diphosphorus Uranium Complex. J. Am. Chem. Soc. 143, 5343-5348 (2021).

14. Martinez JL, Lutz SA, Beagan DM, Gao X, Pink M, Chen C-H, et al. Stabilization of the Dinitrogen Analogue, Phosphorus Nitride. ACS Cent. Sci. 6, 1572-1577 (2020).

15. Kinjo R, Donnadieu B, Bertrand G. Isolation of a Carbene-Stabilized Phosphorus Mononitride and Its Radical Cation (PN+.). Angew. Chem. Int. Ed. 49, 5930-5933 (2010).

16. Velian A, Cummins CC. Facile Synthesis of Dibenzo- $7 \lambda^{3}$-phosphanorbornadiene Derivatives Using Magnesium Anthracene. J. Am. Chem. Soc. 134, 13978-13981 (2012).

17. Hering C, Schulz A, Villinger A. Diatomic PN - trapped in a cyclo-tetraphosphazene. Chem. Sci. 5, 1064-1073 (2014).

18. Niecke E, Nieger M, Reichert F. Arylmino(halogeno)phosphanes $\mathrm{XP}=\mathrm{NC}_{6} \mathrm{H}_{2} t \mathrm{Bu}_{3}(\mathrm{X}=\mathrm{Cl}, \mathrm{Br}$, I) and the Iminophosphenium Tetrachloroaluminate $[\mathrm{P} \equiv \mathrm{NC} 6 \mathrm{H} 2 \mathrm{tBu} 3]^{+}[\mathrm{AlCl} 4]^{-}$: the First Stable Compound with a PN Triple Bond. Angew. Chem. Int. Ed. 27, 1715-1716 (1988).

19. Wyse FC, Manson EL, Gordy W. Millimeter Wave Rotational Spectrum and Molecular Constants of ${ }^{31} \mathrm{P}^{14} \mathrm{~N}$. J. Chem. Phys. 57, 1106-1108 (1972).

20. Tofan D, Velian A. Interstellar Chemistry in a Glovebox: Elusive Diatomic $\mathrm{P} \equiv \mathrm{N}$, Exposed. $A C S$ Cent. Sci. 6, 1485-1487 (2020).

21. Himmel D, Krossing I, Schnepf A. Dative Bonds in Main-Group Compounds: A Case for Fewer Arrows! Angew. Chem. Int. Ed. 53, 370-374 (2014).

22. Courtemanche M-A, Transue WJ, Cummins CC. Phosphinidene Reactivity of a Transient Vanadium $\mathrm{P} \equiv \mathrm{N}$ Complex. J. Am. Chem. Soc. 138, 16220-16223 (2016).

23. Velian A, Nava M, Temprado M, Zhou Y, Field RW, Cummins CC. A Retro Diels-Alder Route to Diphosphorus Chemistry: Molecular Precursor Synthesis, Kinetics of $\mathrm{P}_{2}$ Transfer to 1,3Dienes, and Detection of $\mathrm{P}_{2}$ by Molecular Beam Mass Spectrometry. J. Am. Chem. Soc. 136, 13586-13589 (2014).

24. Transue WJ, Velian A, Nava M, Martin-Drumel M-A, Womack CC, Jiang J, et al. A Molecular Precursor to Phosphaethyne and Its Application in Synthesis of the Aromatic 1,2,3,4Phosphatriazolate Anion. J. Am. Chem. Soc. 138, 6731-6734 (2016).

25. Transue WJ, Nava M, Terban MW, Yang J, Greenberg MW, Wu G, et al. Anthracene as a Launchpad for a Phosphinidene Sulfide and for Generation of a Phosphorus-Sulfur Material 
Having the Composition $\mathrm{P}_{2} \mathrm{~S}$, a Vulcanized Red Phosphorus That Is Yellow. J. Am. Chem. Soc. 141, 431-440 (2019).

26. Riu M-LY, Jones RL, Transue WJ, Müller P, Cummins CC. Isolation of an elusive phosphatetrahedrane. Sci. Adv. 6, eaaz3168 (2020).

27. Gediga M, Burck S, Bender J, Förster D, Nieger M, Gudat D. Specific and Reversible Alkynyl Transfer Reactions of an N-Heterocyclic Phosphane. Eur. J. Inorg. Chem. 2014, 1818-1825 (2014).

28. Hansen PE. Isotope Effects on Nuclear Shielding. In: Webb GA (ed). Annual Reports on NMR Spectroscopy, vol. 15. Academic Press, 1984, pp 105-234.

29. Hansen PE. Isotope effects in nuclear shielding. Prog. Nucl. Magn. Reson. Spectrosc. 20, 207255 (1988).

30. Ahmad IK, Hamilton PA. The Fourier Transform Infrared Spectrum of PN. J. Mol. Spectrosc. 169, 286-291 (1995).

31. Dillon KB, Platt AWG, Waddington TC. The identification of some new azido-derivatives of phosphorus. Inorg. Nucl. Chem. Letters 14, 511-513 (1978).

32. Buder W, Schmidt A. Phosphorazide und deren Schwingungsspektren. Z. Anorg. Allg. Chem. 415, 263-267 (1975).

33. Gilyarov VA. Phosphorus Acid Azides. Russ. Chem. Rev. 51, 909-920 (1982).

34. Holleman AF. Lehrbuch der anorganischen Chemie. Walter de Gruyter GmbH \& Co KG, 2019.

35. Dielmann F, Back O, Henry-Ellinger M, Jerabek P, Frenking G, Bertrand G. A Crystalline Singlet Phosphinonitrene: A Nitrogen Atom-Transfer Agent. Science 337, 1526 (2012).

36. Staudinger H, Meyer J. Über neue organische Phosphorverbindungen III. Phosphinmethylenderivate und Phosphinimine. Helv. Chim. Acta 2, 635-646 (1919).

37. Transue WJ, Velian A, Nava M, García-Iriepa C, Temprado M, Cummins CC. Mechanism and Scope of Phosphinidene Transfer from Dibenzo-7-phosphanorbornadiene Compounds. J. Am. Chem. Soc. 139, 10822-10831 (2017).

38. Hamon P, Toupet L, Roisnel T, Hamon J-R, Lapinte C. Preparation and Characterization of the Triflate Complex [Cp*(dppe)FeOSO $\mathrm{CF}_{3}$ ]: A Convenient Access to Labile Five- and SixCoordinate Iron(I) and Iron(II) Complexes. Eur. J. Inorg. Chem. 2020, 84-93 (2020).

39. Huber K-P. Molecular spectra and molecular structure: IV. Constants of diatomic molecules. Springer Science \& Business Media, 2013.

40. Knizia G. Intrinsic Atomic Orbitals: An Unbiased Bridge between Quantum Theory and Chemical Concepts. J. Chem. Theory Comput. 9, 4834-4843 (2013).

41. Niecke E, Detsch R, Nieger M, Reichert F, Schoeller W. From covalent to ionic bonding: spontaneous bond dissociation in oxy-substituted iminophosphanes. Bull. Soc. Chim. Fr. 130, 25-31 (1993).

42. Kraka E, Freindorf M. Characterizing the Metal-Ligand Bond Strength via Vibrational Spectroscopy: The Metal-Ligand Electronic Parameter (MLEP). In: Lledós A, Ujaque G (eds). New Directions in the Modeling of Organometallic Reactions. Springer International Publishing: Cham, 2020, pp 227-269.

43. Prisecaru I. WMOSS4 Mößbauer Spectral Analysis Software. 2009-2016 [cited 08/24/2021]Available from: www.wmoss.org.

44. Rittle J, Peters JC. Fe- $\mathrm{N}_{2} / \mathrm{CO}$ complexes that model a possible role for the interstitial C atom of FeMo-cofactor (FeMoco). Proc. Natl. Acad. Sci. USA 110, 15898 (2013).

45. Latypov SK, Polyancev FM, Yakhvarov DG, Sinyashin OG. Quantum chemical calculations of ${ }^{31}$ P NMR chemical shifts: scopes and limitations. Phys. Chem. Chem. Phys. 17, 6976-6987 (2015).

46. Schneider WB, Bistoni G, Sparta M, Saitow M, Riplinger C, Auer AA, et al. Decomposition of Intermolecular Interaction Energies within the Local Pair Natural Orbital Coupled Cluster Framework. J. Chem. Theory Comput. 12, 4778-4792 (2016).

47. Mitoraj MP, Michalak A, Ziegler T. A Combined Charge and Energy Decomposition Scheme for Bond Analysis. J. Chem. Theory Comput. 5, 962-975 (2009).

48. Altun A, Neese F, Bistoni G. Effect of Electron Correlation on Intermolecular Interactions: A Pair Natural Orbitals Coupled Cluster Based Local Energy Decomposition Study. J. Chem. Theory Comput. 15, 215-228 (2019). 
49. Stanford University Environmental Health \& Safety. Information on Azide Compounds. [cited 08/24/2021] https://ehs.stanford.edu/reference/information-azide-compounds.

50. Pangborn AB, Giardello MA, Grubbs RH, Rosen RK, Timmers FJ. Safe and Convenient Procedure for Solvent Purification. Organometallics 15, 1518-1520 (1996).

51. Williams DBG, Lawton M. Drying of Organic Solvents: Quantitative Evaluation of the Efficiency of Several Desiccants. J. Org. Chem. 75, 8351-8354 (2010).

52. Roger C, Hamon P, Toupet L, Rabaa H, Saillard JY, Hamon JR, et al. Halo- and alkyl(pentamethylcyclopentadienyl)[1,2-bis(diphenylphosphino)ethane]iron(III) 17-electron complexes: synthesis, NMR and magnetic properties and EHMO calculations. Organometallics 10, 1045-1054 (1991).

53. Patel D, Wooles A, Cornish AD, Steven L, Davies ES, Evans DJ, et al. Synthesis and characterisation of halide, separated ion pair, and hydride cyclopentadienyl iron bis(diphenylphosphino)ethane derivatives. Dalton Trans. 44, 14159-14177 (2015).

54. Fulmer GR, Miller AJM, Sherden NH, Gottlieb HE, Nudelman A, Stoltz BM, et al. NMR Chemical Shifts of Trace Impurities: Common Laboratory Solvents, Organics, and Gases in Deuterated Solvents Relevant to the Organometallic Chemist. Organometallics 29, 2176-2179 (2010). 